\title{
Screening of Inbred Lines and Hybrids/composites Against Common Rust of Maize under Field Conditions
}

\author{
Utpal Dey $^{1 *}$, S. I. Harlapur ${ }^{1}$, D. N. Dhutraj ${ }^{2}$ and Anup Das ${ }^{3}$
}

${ }^{1}$ Dept. of Plant Pathology, University of Agricultural Sciences, Dharwad, Karnataka (580 005), India

${ }^{2}$ Dept. of Plant Pathology, Vasantrao Naik Marathwada Krishi Vidyapeeth (VNMKV), Parbhani, Maharashtra (431 402), India

${ }^{3}$ ICAR Research Complex for North Eastern Hill Region, Umiam, Meghalaya (793 103), India

\section{Corresponding Author}

Utpal Dey

e-mail: utpaldey86@gmail.com

\author{
Article History \\ Article ID: AR1810e \\ Received in $27^{\text {th }}$ April, 2017 \\ Received in revised form $27^{\text {th }}$ July, 2017 \\ Accepted in $6^{\text {th }}$ August, 2017
}

\begin{abstract}
The biotrophic fungus Puccinia sorghi Schw. is one of the most devastating pathogen causing significant yield losses in maize production and productivity. Although, chemical pesticide measures are effective in reducing yield losses, yet their use is restricted due to the high cost involvement and residual toxicity affecting the ecological balance. Thus, for minimizing the losses due to the disease, it is necessary to introgress an adequate level of genetic resistance against the disease having economic importance that will reduce the use of chemical pesticides. A field experiment has been conducted in the farm of Main Agricultural Research Station, College of Agriculture, University of Agricultural Sciences, Dharwad, Karnataka, India, on the screening of different inbred lines and hybrids/composites against common rust of maize incited by Puccinia sorghi Schw. The experiment was laid down in a randomized block design (RBD) with three replications. Significant differences in resistance to common rust of maize were found among the maize inbreds and hybrids tested. Among the 43 inbred lines 2 inbred lines viz., Indimyt 345 and MI-12 registered highly resistant reaction. Of the 43 hybrids/composites evaluated 14 lines, viz., NK-6240, NK-61, NK-7305, CP-808, GK-3090, 30R77, CP-818, C-1945, JKMH-502, PAC-740, NK-121, Pro-311 and DK-984 registered resistant reaction against $P$. sorghi. The study reveals that the nature of resistance to $P$. sorghi is inheritable as the hybrids derived from resistant inbreds were more resistant than those hybrids derived from the susceptible parents. The study concludes that screening parental inbred lines for resistance to $P$. sorghi is an important step in developing maize hybrids with improved resistance to $P$. sorghi.
\end{abstract}

Keywords: Common rust, maize, puccinia sorghi, resistance, Zea mays

\section{Introduction}

Maize (Zea mays L.) is the most versatile crop, adapted to different agro-ecological and climatic conditions. It is the third most important cereal crop next to rice and wheat in India. It is one of the potential crop of Karnataka which has come up on large areas in different districts under rainfed areas and under irrigated command areas of Ghataprabha, Malaprabha, Tungabhadra, Bhadra and Upper Krishna. The average maize yield in India is $1785 \mathrm{~kg} \mathrm{ha}^{-1}$. The Karnataka state has maximum area of 12.37 lakh ha with production of 30.07 lakh $t$ and productivity $2540 \mathrm{~kg} \mathrm{ha}^{-1}$ (Anonymous, 2010). In Karnataka about $6 \%$ land is under maize production with $12 \%$ share in India's production. The main season for growing maize is kharif, covering an area of $86 \%$, out of which $60 \%$ comes under irrigation and about $90 \%$ area is covered by hybrids. Maize is attacked by many diseases in kharif, rabi and summer seasons causing severe reduction in yield. Among all the foliar diseases, common rust of maize caused by Puccinia sorghi Schw is one of the devastating disease in India. Roduel Rodriguez et al.
(1980) reported that common rust cause yield loss up to $45 \%$. Danson et al. (2008) reported that common rust diseases can greatly reduce grain yield in susceptible genotypes of maize up to $40 \%$ on an average. Several reports indicate that differences in resistance to common rust of maize caused by $P$. sorghi exist in maize inbred lines and hybrids/composites. The objective of this study was to assess the maize inbred lines and their hybrids for resistance to common rust under field conditions.

\section{Materials and Methods}

Maize inbred lines developed in India were tested for resistance to common rust under field conditions. Forty three maize inbred lines were collected from AICMIP (All India Coordinated Maize Improvement Project), Agricultural Research Station, Arabhavi, University of Agricultural Sciences, Dharwad, Karnataka, and Directorate of Maize Research, Indian Council of Agricultural Research, New Delhi. These lines were screened in field under artificial epiphytotic conditions of disease development during kharif 2010 at 
Main Agricultural Research Station, Dharwad, University of Agricultural Sciences, Dharwad. Forty three maize genotypes comprised of composites, commercially cultivated private and public sector hybrids and experimental hybrids were screened in the field under artificial epiphytotic conditions. The test lines were sown in a randomized block design with the plot of $5 \times 3 \mathrm{~m}^{2}$ size spaced at $60 \times 30 \mathrm{~cm}^{2}$ and replicated thrice. Four spreader rows with highly susceptible genotype CM-202 were planted on either side of the screening block. Recommended agronomic practices and insect pest control measures were followed as per the package of practices of University of Agricultural Sciences, Dharwad (Anonymous, 2003).

The propagating spores i.e., uredospores were gathered from the naturally infested leaves collected from different places so as to get all the prevalent races in the areas that would be effectively utilized for screening the materials against the disease. The infected leaves thus collected were macerated thoroughly in between two palms of the hands dipped under a bucket of water until the water gets sufficiently coloured. The uredospores thus obtained were kept in freezer at $5-7^{\circ} \mathrm{C}$ and used for further inoculation purposes. With the help of knapsack sprayer, the test plants materials were inoculated with the uredospores. The spore suspension was sprayed thoroughly over the plants during evening hours and repeated twice to get high disease pressure. Further, the genotypes were categorized as resistant, moderately resistant, susceptible and highly susceptible based on 1-5 disease severity rating scale.

Disease rating was recorded at silk drying stage on 1-5 scale as described below:

1. Highly resistant : Very slight to slight infection, one or two to few scattered pustules on lower leave only.

2. Resistant : Moderate number of pustules on lower leaves only (light infection)

3. Moderately resis- : Abundant pustule on lower tant leaves, few on middle leaves (moderate infection)

4. Susceptible : Abundant pustules on lower and middle leaves, extending to upper leaves (heavy infection)

5. Highly susceptible : Abundant pustules on all leaves, plant mass prematurely dry or be killed by the disease (very heavy infection)

At maturity, grain yield was recorded and data was computed using standard statistical methods.

\section{Results and Discussion}

\subsection{Resistance to common rust in maize inbreds}

Continuous efforts to locate the resistant sources and then utilization in resistance breeding programme are crucial stride to manage the disease in the long term. Screening was therefore undertaken to evaluate large number of inbred line collections against $P$. sorghi under artificially inoculated uniform rust nursery conditions during kharif, 2010. The lines were evaluated based on 1-5 disease rating scale. The reaction of various lines is presented in Table 1 and 2 . Significant

Table 1: Screening of maize inbred lines against common rust caused by $P$. sorghi

\begin{tabular}{|c|c|c|}
\hline SI. No. & Inbred lines & Rust score (1-5 scale) \\
\hline 1. & $\mathrm{Cl}-4$ & 2 \\
\hline 2. & CML-441 & 4 \\
\hline 3. & $\mathrm{MI}-12$ & 1 \\
\hline 4. & CM-144 & 2 \\
\hline 5. & KDMI-15 & 4 \\
\hline 6. & NEI 9202 B & 2 \\
\hline 7. & CML-118 & 4 \\
\hline 8. & CML-41 & 5 \\
\hline 9. & CM-111 & 3 \\
\hline 10. & CM-139 & 4 \\
\hline 11. & $\mathrm{MI}-44$ & 5 \\
\hline 12. & HYD. Sel.14 & 4 \\
\hline 13. & HYD. Sel.17 & 2 \\
\hline 14. & CM-135 & 4 \\
\hline 15. & MG-4 & 3 \\
\hline 16. & $\mathrm{Cl}-5$ & 3 \\
\hline 17. & KDMI-4 & 3 \\
\hline 18. & CM-118 & 3 \\
\hline 19. & HYD. Sel.2 & 2 \\
\hline 20. & HYD. Sel.4 & 4 \\
\hline 21. & CML-169 & 4 \\
\hline 22. & CM-400 & 4 \\
\hline 23. & CM-138 & 4 \\
\hline 24. & CM-600 & 4 \\
\hline 25. & CM-601 & 4 \\
\hline 26. & CM-122 & 3 \\
\hline 27. & CM-125 & 4 \\
\hline 28. & NAI-104 & 2 \\
\hline 29. & NAI-147 & 3 \\
\hline 30. & Indimyt-345 & 1 \\
\hline 31. & CM-124 & 4 \\
\hline 32. & CM-211 & 5 \\
\hline
\end{tabular}

Continue... 


\begin{tabular}{lcc}
\hline SI. No. & Inbred lines & Rust score (1-5 scale) \\
\hline 33. & HYD. Sel.12 & 4 \\
34. & KDMI-9 & 3 \\
35. & CM-136 & 5 \\
36. & CM-208 & 4 \\
37. & KDMI-10 & 4 \\
38. & CM-129 & 4 \\
39. & CM-131 & 4 \\
40. & CM-501 & 3 \\
41. & CM-119 & 2 \\
42. & NAI-113 (Resistant check) & 2 \\
43. & CM-202 (Susceptible & 5 \\
\hline
\end{tabular}

Table 2: Reaction of maize inbred lines against $P$. sorghi under field conditions

\begin{tabular}{|c|c|c|c|}
\hline $\begin{array}{l}\text { Disease } \\
\text { rating }\end{array}$ & Reaction & $\begin{array}{l}\text { No. of } \\
\text { entries }\end{array}$ & Inbred lines \\
\hline 1 & $\begin{array}{l}\text { Highly resis- } \\
\text { tant }\end{array}$ & 2 & MI-12, Indimyt-345 \\
\hline 2 & Resistant & 8 & $\begin{array}{l}\text { Cl-4, CM-144, NEI-9202B, } \\
\text { HYD. Sel.17, HYD Sel.2, } \\
\text { NAI-104, NAI-113, CM- } \\
119\end{array}$ \\
\hline 3 & $\begin{array}{l}\text { Moderately } \\
\text { resistant }\end{array}$ & 9 & $\begin{array}{l}\text { CM-111, MG-4, CI-5, } \\
\text { KDMI-4, CM-118, CM- } \\
\text { 122, NAI-147, KDMI-9, } \\
\text { CM-501 }\end{array}$ \\
\hline 4 & Susceptible & 19 & $\begin{array}{l}\text { CML-441, KDMI-15, CML- } \\
\text { 118, CM-139, HYD. Sel.14, } \\
\text { CM-135, HYD. Sel.4, CML- } \\
\text { 169, CM-400, CM-138, } \\
\text { CM-600, CM-601, CM- } \\
\text { 125, CM-124, CM-208, } \\
\text { KDMI-10, CM-129, CM- } \\
\text { 131, HYD. Sel.-12 }\end{array}$ \\
\hline 5 & $\begin{array}{l}\text { Highly sus- } \\
\text { ceptible }\end{array}$ & 5 & $\begin{array}{l}\text { CM-202, CML-41, MI-44, } \\
\text { CM-211, CM-136 }\end{array}$ \\
\hline
\end{tabular}

variations in disease severity index (1-5 scale) for common rust of maize were observed in various lines. Of the 43 inbred line collections evaluated, only 2 lines, viz., Indimyt 345 and MI-12 registered highly resistant reaction, 8 lines were identified as resistant, 9 lines found moderately resistant and remaining were susceptible. These findings will help to develop new set of agronomically desirable and disease resistant hybrids that would enhance and sustain the maize production and productivity. The character of resistance to common rust of maize can be transferred from the identified resistant sources to the high yielding susceptible genotypes by using pedigree method or backcross method of breeding.

\subsection{Resistance to common rust in maize hybrids/composites}

Totally 43 maize genotypes were screened against $P$. sorghi under artificially inoculated field conditions during kharif 2010. The genotypes showed considerable variation in disease reaction. Disease intensity was observed as low (2) to very severe (4) among various genotypes tested. Among the large number of genotypes screened, no genotype were registered highly resistant reaction, 14 genotypes were rated as resistant. 11 genotypes expressed moderately resistant reaction, whereas rest of the genotype was susceptible (Tables 3 and 4). Hybrids namely, NK-6240, NK-61, NK-7305, CP-808, GK3090, 30R77, CP-818, C-1945, JKMH-502, PAC-740, NK-121, Pro-311 and DK-984 registered resistant reaction against $P$. sorghi. Among the composites, Swarna registered resistant reaction. The composite GC-1005 was rated as moderately resistant. However, three composites, viz., G-25, Kiran and Prakash were severely affected by common rust of maize and rated as susceptible.

Field screening studies indicated that there was clear cut differential disease response of inbred lines to $P$. sorghi due to artificial inoculation. Also, the inbred lines showing moderately resistant reaction of less than 3.0 disease score remained green till maturity, while highly susceptible lines ( $>4.0$ score) failed to produce normal foliage as well as ears as disease covered the entire plant before silking and tasseling stage (Table 3 and 4 ).

Table 3: Screening of maize genotypes against common rust caused by P. sorghi

\begin{tabular}{llc}
\hline Sl. No. & Genotypes & Rust score (1-5 scale) \\
\hline 1. & EH-434042 & 3 \\
2. & All rounder & 3 \\
3. & DMH-2 & 4 \\
4. & NK-6240 & 2 \\
5. & NAC-6004 & 3 \\
6. & C-1921 & 3 \\
7. & C-1837 & 4 \\
8. & C-1945 & 4 \\
9. & C-6485 & 4 \\
10. & Bio-9681 & 4 \\
11. & $900 M$ & 3 \\
12. & NK-61 & 2 \\
13. & NK-7305 & 2 \\
14. & CP-828 & 4 \\
15. & CP-808 & 2 \\
16. & GK-3090 & 2 \\
\hline
\end{tabular}




\begin{tabular}{|c|c|c|}
\hline SI. No. & Genotypes & Rust score (1-5 scale) \\
\hline 17. & GK-3060 & 4 \\
\hline 18. & HMH-9045 & 3 \\
\hline 19. & DKC-8101 & 4 \\
\hline 20. & Prabal & 3 \\
\hline 21. & TG-8421 & 4 \\
\hline 22. & Suraj & 3 \\
\hline 23. & $30 R 77$ & 2 \\
\hline 24. & CP-818 & 2 \\
\hline 25. & MRM-3838 & 4 \\
\hline 26. & C-1945 & 2 \\
\hline 27. & Kaveri-235 & 3 \\
\hline 28. & JKMH-502 & 2 \\
\hline 29. & PAC-740 & 2 \\
\hline 30. & $\mathrm{KH}-517$ & 4 \\
\hline 31. & NK-121 & 2 \\
\hline 32. & Kaveri-225 & 4 \\
\hline 33. & Pro-4642 & 3 \\
\hline 34. & $\mathrm{NMH}-145$ & 4 \\
\hline 35. & Pro-311 & 2 \\
\hline 36. & DHM-105 & 4 \\
\hline 37. & DK-984 & 2 \\
\hline 38. & G-25 & 4 \\
\hline 39. & GC-1005 & 3 \\
\hline 40. & Kiran & 4 \\
\hline 41. & Prakash & 4 \\
\hline 42. & $\begin{array}{l}\text { Amar-606 (Susceptible } \\
\text { check) }\end{array}$ & 4 \\
\hline 43. & Swarna (Resistant check) & 2 \\
\hline
\end{tabular}

The present study revealed that out of 43 inbred lines tested, only 2 lines registered high level of resistance (HR) which have recorded least disease rating of 1.0, while susceptible check CM-202 had exhibited maximum rating scale of 4.0. This suggests that the disease development was highly satisfactory and the categorization of materials into different classes is valid and appropriate. The investigation revealed that 2 inbred lines, namely Indimyt 345 and $\mathrm{Ml}-12$ had registered highly resistant reaction which possessed a disease score of 1.0.

Thus, it can be emphasized from the results that the identified highly resistant and resistant lines hold excellent promise for resistance against $P$. sorghi causing common rust of maize and can be used for developing hybrids and composites in future programme of breeding for disease resistance.

Patil et al. (2000) reported that inbred lines $\mathrm{Cl}-4$, NAI-113 and CM-501 found moderately resistant to common rust. Sharma
Table 4: Reaction of maize genotypes against $P$. sorghi under field conditions

\begin{tabular}{llll}
\hline $\begin{array}{l}\text { Disease } \\
\text { Rating }\end{array}$ & $\begin{array}{l}\text { Reaction } \\
\text { tries }\end{array}$ & $\begin{array}{l}\text { No of en- } \\
\text { tienotypes }\end{array}$ \\
\hline 1 & $\begin{array}{l}\text { Highly resis- } \\
\text { tant }\end{array}$ & & Nil
\end{tabular}

2 Resistant $14 \quad$ NK-6240, NK-61, NK7305, CP-808, GK3090, 30R77, CP-818, C-1945, JKMH-502, PAC-740, NK-121, Pro311, DK-984, Swarna

3 Moderately $11 \quad$ EH-434042, Allroundresistant er, NAC-6004, C-1921, 900M, GC-1005, HMH9045, Prabal, Suraj, Kaveri-235, Pro-4642

4 Susceptible 18 DMH-2, G-25, C-1837, C-1945, C-6485, Bio9681, CP-828, GK3060, DKC-8101, TG-8421, MRH-3838, Amar-606, $\mathrm{KH}-517$, Kaveri-225, $\mathrm{NMH}-$ 145, Kiran, DMH-105, Prakash

$5 \quad$ Highly sus- _ N Nil ceptible

and Payak (1979) observed that resistance to common rust is controlled by polygenes and further reported that, inbred lines GE 440, CM 105 and CM 104 being the best general combiners of resistance. Kumar et al. (1989) found that out of 79 maize genotype screened for resistant to $P$. sorghi, hybrids, EH 5041 and EH 5091 were resistant. Dhanju and Das (2005) noticed that lines viz., HKI-295, HKI 1354, HKI 1348-6 and HKI 488 were most important, productive, disease resistant lines which were incorporated in hybrids such as $\mathrm{HHM}-1, \mathrm{HM}-5$ and HM-6 which are resistant to common rust.

Out of total 43 maize genotypes screened, none was found to be highly resistant against the disease. Eighteen genotypes were found resistant. Eleven genotypes showed moderately resistant reaction, whereas rests of the tested genotypes were found to be susceptible. Among the genotypes evaluated against common rust of maize, one composite Swarna and 13 commercial hybrids, viz., NK-6240, NK-61, NK-7305, CP808, GK-3090, 30R77, CP-818, C-1945, JKMH-502, PAC-740, NK-121, Pro-311 and DK-984 were found to posses resistant reaction.

Sinha et al. (1974) described that among 35 cultivars studied, 
J1 syn 16, J1 Mexican JWC, R2 syn 29 and EH 407 were resistant to common rust in Bihar. Widrlechner and Dragula (1992) recorded that OC $1, O C 5$ and OC 11 had good field resistant to corn rust. Kumar et al. (1989) screened 79 maize genotypes for resistant to $P$. sorghi, the hybrids, EH 5041 and EH 5091 were resistant. Thus the promising high yielding common rust of maize resistant genotypes identified through this investigation can be deployed in disease endemic areas to aim for sustainable productivity.

The study confirms existence of variability in resistance to common rust in different germplasms of maize were observed in this experimental study. The resistant nature of inbred lines CM-501observed in present field trails confirmed the report by Patil et al. (2000) and susceptible nature of the inbred line CM-400 confirm the reports by the Bazzalo et al. (1991) and Kolte (1976). These findings suggested that it is possible to improve an existing inbred through further selection and screening of the progenies of the parental line.

\section{Conclusion}

Maize inbreds MI-12, Indimyt-345, Cl-4, CM-144, NEI-9202B, HYD. Sel.17, HYD Sel.2, NAI-104, NAI-113, CM-119 were rated as highly resistant/resistant and hybrids/composites NK-6240, NK-61, NK-7305, CP-808, GK-3090, 30R77, CP818, C-1945, JKMH-502, PAC-740, NK-121, Pro-311, DK-984 and Swarna were rated as resistant against the pathogen under field conditions. These inbred lines with superior rust resistant traits could be used as genetic materials for the breeding of hybrids suitable for rainfed ecosystem and further development of disease resistance population.

\section{References}

Anonymous, 2003. Package of Practices for Improved Cultivation of Crops. Publication Centre, Directorate of Extension, University of Agricultural Sciences, Dharwad, 26.

Anonymous, 2010. 54 ${ }^{\text {th }}$ Annual Progress Report, All India Coordinated Maize Research Project, Directorate of Maize
Research, New Delhi, 15.

Bazzalo, M.E., Dimarco, F., Martinez, F., Daleo, G.R., 1991. Indicators of resistance of sunflower plant to basal stalk rot (Sclerotinia sclerotiorum): Symptomatological, biochemical, anatomical, and morphological characters of the host. Euphytica 57, 195-205.

Danson, J., Martin Lagat, M., Kimani, M., Kuria, A., 2008. Quantitative Trait Loci (QTLs) for resistance to gray leaf spot and common rust diseases of maize. African Journal of Biotechnology 7(18), 3247-23254.

Dhanju, K.S., Dass, S., 2005. Identification of multiple disease resistant lines and their use in developing disease free maize hybrids. Annals of Agricultural Biological Research 10(1), 35-237.

Kolte, S.J., Singh, B., Tewari, A.N., 1976. Evaluation of sunflower genotypes for resistance to Sclerotinia sclerotiorum. Indian Journal of Mycology and Plant Pathology 6, 65-267.

Kumar, N., Dass, S., Singh, M., 1989. Evaluation of germplasm for resistance to the common rust of maize. Agricultural Science Digest Karnal 9(2), 67-269.

Patil, S.J., Wali, M., Harlapur, S.I., Prashant, M., 2000. Maize Research in North Karnataka Technical Bulletin, All India Coordinated Maize Improvement Project, University of Agricultural Sciences, Dharwad, 54.

Roduel Rodriguez-Ardon, G.E., Scott, King, S.B., 1980. Maize yield losses caused by southern maize rust. Crop Science 20, 812-2814.

Sharma, R.C., Payak, M.M., 1979. Resistance to common rust of maize in India. Maize Genetics Cooperation News letter, 53, 65-266.

Sinha, D.C., Mishra, B., Misra, A.P., 1974. Reaction of maize cultivars to Puccinia sorghi in Bihar. Indian Phytopathology 27(2), 253-2254.

Widrlechner, M.P., Dragula, S.K., 1992. Eleven ornamental corn inbreeds lines oc1 through oc11, Hort Science 27(12), 1338-21339. 